\title{
Antipsychotic Polypharmacy Versus Monotherapy in Elderly Patients with Chronic Schizophrenia: A Clinical Trial
}

\author{
Arash Mirabzadeh', Hashem Shemshadi ${ }^{2}$, Mohammad Reza Khodaei $^{3}$, Gita Sadighi ${ }^{4}$, Sara Hashempour ${ }^{5}$, \\ Hossein Mirabzadeh ${ }^{6}$, Akbar Biglarian ${ }^{7}$
}

\section{ABSTRACT:}

Antipsychotic polypharmacy versus monotherapy in elderly patients with chronic schizophrenia: a clinical trial

\begin{abstract}
Objective: Antipsychotic polypharmacy in the elderly usually results in higher rates of interactions, side effects and increased cost. This research was designed to observe the benefits of replacing polypharmacy with a single medication in elderly patients with chronic schizophrenia.
\end{abstract}

Methods: This was a quasi-experimental, prospective, descriptive and analytical clinical trial. A survey was performed at the long stay public and academic Tehran Razi Mental Hospital. From the initial 157 conveniently access patients, 59 cases were selected based on inclusion and exclusion criteria. Before intervention, 7 patients did not participate in the study due to the recent diagnosis of new medical conditions. Fifty-two (52) cases (males=13 and females $=39$ ) entered and completed the 36 week research time period. At baseline 40 patients were receiving two types of antipsychotics, whereas, 11 patients were receiving three types and only 1 patient was receiving four types of antipsychotic drugs. In the pre-intervention period, the approval of the University's ethics committee and the informed consents of the patients' relatives were obtained. Systematically, the patients' multiple antipsychotics were switched to a single medication, risperidone. After determining the equivalent dose of risperidone, it was started at $1 \mathrm{mg} / \mathrm{day}$ for all patients. After a 3-6 week cross-titration period, the patients reached the previously determined equivalent risperidone doses and completed 36 weeks until the end of the study. Clinical assessments including the Brief Psychotic Rating Scale (BPRS), Global Assessment of Functioning (GAF), and Extra-Pyramidal Syndrome (EPS) Scale were applied on a weekly basis for a 36 week period.

Results: The mean BPRS scores of the participants showed statistically significant improvement after the $9^{\text {th }}$ week of intervention. Improvements were observed in all symptom dimensions of the BPRS (positive, negative and general schizophrenic symptoms). At the end of 36 weeks of risperidone use, $90.1 \%$ of the patients achieved at least a $50 \%$ reduction in their symptoms. Additionally, functional improvement and a lower incidence of extrapyramidal side effects were also achieved after 36 weeks of risperidone use in the study population.

Conclusion: Risperidone may be considered safe as a monotherapy alternative for elderly patients with chronic schizophrenia who are being treated with multiple concomitant antipsychotics. This replacement may result in some clinical benefits and fewer side effects.

Keywords: schizophrenia, antipsychotic medications, elderly, polypharmacy, monotherapy

Bulletin of Clinical Psychopharmacology 2014;24(4):302-10
'Professor of Psychiatry, Social Determinants of Health Research Center and Department of Psychiatry, University of Social Welfare and Rehabilitation Sciences, Iran

${ }^{2}$ Professor., University of Social Welfare and Rehabilitation Sciences, Department of Reconstructive Surgery, Iran ${ }^{3}$ Assoc. Prof., ${ }^{4}$ Assist. Prof,

${ }^{5} \mathrm{M}$.D., Psychiatry Resident, University of Social Welfare and Rehabilitation Sciences, Department of Psychiatry, Iran ${ }^{6}$ Master, Industrial Psychology, Refah Bank, Iran

${ }^{7}$ Assist. Prof., University of Social Welfare and Rehabilitation Sciences, Department of Biostatistics, Iran

Corresponding author: Dr. Hashem Shemshadi, University of Social Welfare and Rehabilitation Sciences, Department of Reconstructive Surgery, Iran

E-mail address:

shemshadii@gmail.com

Date of submission:

January 28, 2014

Date of acceptance: July 01,2014

Declaration of interest: A.M., H.S., M.R.K., G.S., S.H., H.M., A.B.: The authors reported no conflict of interest related to this article.

\section{INTRODUCTION}

Polypharmacy is defined as the treatment of a patient with 2 or more antipsychotic medications ${ }^{1}$. Our main goal was to observe the benefits of replacing multiple antipsychotics with a single medication in elderly patients with chronic schizophrenia. Worldwide, irrational medical therapy is considered to be one of the most complicated issues in health care. Nonstandardize medical applications such as inappropriate prescription and dose, wrong route of administration (e.g. IM instead PO) and patient self-medication, are current dilemmas of medical 
therapy worldwide ${ }^{1}$. There is not a common definition for polypharmacy among scientists, but generally it is considered to be when at two or more medications with different mechanisms are used simultaneously. Some scientists consider it to be "minor polypharmacy" when 2-4 drugs and "major pharmacy" when more than 5 medications are used ${ }^{2}$. Polypharmacy is considered to be a "rule" rather than an "exception" in psychiatry ${ }^{2}$. Many patients have been prescribed multiple medications prior to their hospital discharge or after being seen in mental clinics ${ }^{2}$. Mental patients are at more risk of being treated with polypharmacy in comparison to other medical disorders ${ }^{2}$. Polypharmacy escalates medical risks for interactions, side effects, severe health hazards, and periods of hospitalization, and decreases patients` quality of life. In special circumstances where the use of a single medication has failed, polypharmacy may be considered with an understanding of pharmacodynamics, pharmacokinetics, animal and human research. Elderly females are more at risk of using polypharmacy ${ }^{3}$. As the courses of different diseases continue, the chance of using polypharmacy increases ${ }^{3,4}$.

Polypharmacy is also defined as using two or more medications in treating diseases, which all share the same mechanism of action; however, using sertraline for depression, along with metformin for diabetics in the same patient, is not considered to be polypharmacy ${ }^{5,6}$. There is a "guideline for polypharmacy" which helps doctors not to prescribe multiple drugs ${ }^{7}$. Other terminologies include: "same class polypharmacy" e.g., is using two selective serotonin reuptake inhibitors (SSRIs); "multi-class polypharmacy" e.g., treating depression with fluoxetine and olanzapine; "adjunctive polypharmacy" e.g., treating insomnia with trazodone and bupropion) and finally "total polypharmacy" e.g., using identical medications ${ }^{7}$. Some drugs may be composed of different neurotransmitter actions integrated as one pill, which is called "polypharmacy-in-a-pill". Some other prescriptions may have fixed actions in combination, which are named "fixed combinations" ${ }^{8}$. Sometimes polypharmacy is applied based on empiric evidence, which is not scientific and not acceptable. Sometimes empiricism is considered rational and valid when it is supported by evidence such as lithium for depression, which is based on several double blind studies $^{9-11}$. The elderly have a metabolism rate is slower in comparison with younger adults because renal and hepatic functions become slower due to the ageing process ${ }^{12-14}$. This latter fact is more serious in patients with chronic schizophrenia ${ }^{15}$. Psychiatrists may be the cause of polypharmacy complications because they have less knowledge of drug pharmacodynamics and pharmacokinetics ${ }^{16}$. Fewer studies have examined the occurrence of polypharmacy in psychiatry. Some clinical trial research has studied the combination of an atypical with typical antipsychotics ${ }^{17}$. In bipolar disorders, the use of lithium with valproic acid, lithium with carbamazepine and carbamazepine with valproic acid has been reported to have significant validity. Using gabapentin was not found to be valid in such "multi-class polypharmacy"18-20. There is a guideline for using polypharmacy in chronic schizophrenia, the "Texas Medical Algorithm Project Guideline”. This guideline emphasizes an initial five steps for "monopharmacy" use and supports adding another antipsychotic medication only if the prior 5 steps have not been effective $^{21-23}$. Discrepancies exist in different reports for the dosing of antipsychotics in chronic schizophrenic patients, but all agree to start polypharmacy at a low dose $\mathrm{e}^{24-27}$. Sixteen percent (16\%) of the population of the USA are over 60 years. This population uses almost $40 \%$ of all prescribed medications annually and 30,000 people die each year due to polypharmacy complications ${ }^{28}$. In Iran, the population over 60 years is $6.6 \%$ ( 4 million) and it is estimated to increase to 10 million by the year 2021. Thirty-six percent of the United Kingdom population is over 65 and $36 \%$ over 75 years. The rate of polypharmacy ( $>4$ medications) in this aforementioned country is high. Sim et al. (2004) 
found polypharmacy to occur at a rate of $45.7 \%$ in elderly and chronically ill patients ${ }^{28}$. Singapore researchers have reported the rate of polypharmacy in their people to be $59 \%$ in previous years and $73 \%$ in $2000^{29}$. By studying the literature, we were encouraged to examine the benefits of replacing polypharmacy with a single medication in elderly patients with chronic schizophrenia.

\section{METHODS and MATERIALS}

This was a prospective, quasi-experimental survey, which was given to elderly patients with a typical diagnosis of chronic schizophrenia, prior to their study enrolments. The survey was performed at the long stay, public and academic Tehran Razi Mental Hospital. This hospital is one of the greatest mental hospitals in the Middle East, which accepts patients in all age groups. A broad scope of mental disorders is admitted to this hospital, mainly schizophrenia. The main goal of this study was to switch patients` polypharmacy to a single medication. From the initial 157 samples, 59 cases were selected. Before intervention, seven ${ }^{7}$ cases failed to enter the study due to the development of a new condition (e.g., acute myocardial infarction). Fifty-two (52) subjects ( males $=13$ and females $=39$ ) entered and completed the 36 weeks of the trial. Patients inclusion criteria were: 60 years and over; diagnosed as a typical schizophrenia prior to their study enrolment for more than two years; not having any significant co-morbidity; have been treated with at least two antipsychotics; and taking antipsychotics with a dose equivalent to or higher than $500 \mathrm{mg}$ of chlorpromazine. Patients with significant cognitive disorders and/or dementia were excluded from the study. Prior to intervention, the University Ethical Committee`s approval and the informed consents of the patients' relatives were obtained. After the equivalent risperidone dose was determined, it was started $1 \mathrm{mg} /$ day P.O. (injection was not considered) and concurrently the doses of polypharmacy were reduced. After 3-6 weeks of such systematic replacement, the risperidone dose reached the therapeutic dose level and the polypharmacy had been changed to risperidone therapy alone. In the majority of patients, this fixed type of cross-tapering showed no remarkable discomfort, except in 5 patients who needed clonazepam (1-2mg/day P.O) for reducing their anxiety, restlessness and behavioral discomfort. The clonazepam medication was gradually discontinued after 3 weeks. Female patients were examined / rated by one psychiatrist and male patients were rated by a different psychiatrist. We used the following validated and reliable tools to assess the trial:

Brief Psychiatric Rating Scale (BPRS): This is one of the most applicable tests used in the field of psychiatry in the world. It has 18 sections which score and compare the patients` positive, negative and general schizophrenic symptoms during their treatment. Patients`symptomatic values of having no (0) to severe (6) symptoms were scored. The comparisons of BPRS positive, negative and the general mean scores at baseline with those measured during the trial at weeks $1,3,6,9,12,24$ and 36 were determined.

Friedman test for Global Assessment of Functioning (GAF): This test scores a patient's degree of psychological, social and occupational awareness. Patients' assessments were recorded based on the test's specific questionnaire codes $^{30-33}$.

Friedman test of Extrapyramidal Symptoms (EPS): This test is widely applied to evaluate the extra pyramidal side effects of antipsychotics ${ }^{30-33}$. The questionnaire is composed of 10 items which measure the EPS side effects from none (0) to severe (4).

Post-intervention, the patients' clinical improvements were scored by using the abovementioned tools, starting from the baseline through the end of 36 th weeks. Data were collected at the end of the trial. The Mann Whitney U test, Wilcoxon signed ranks test and 
Friedman test were used to analysis the data. These statistical analysis was done using SPSS 17 for Windows and $p$ values less than 0.05 were considered significant $(\mathrm{p}<0.05)$.

\section{RESULTS}

The result showed that the patients' polypharmacy types were as follows: 1 patient taking four, 11 taking three and 40 taking two different antipsychotics. Most drug combinations were risperidone + fluphenazine, risperidone + Chlorpromazine and risperidone + haloperidol. There were only 2 patients who were taking two atypical antipsychotics, risperidone + olanzapine. Most other patients were taking one typical and one atypical antipsychotic. None of them used other atypical antipsychotics except risperidone and olanzapine. All, except 6 , used at least one kind of atypical antipsychotic (Table 1). Table 1 shows fluphenazine decanoate was prescribed most often. The reason for this finding may not be related to enhancing medication compliance, but to the accessibility of the drug and the patients' clinical situation.

The BPRS test was used to evaluate the patients` positive, negative and general clinical manifestations. A statistically significant difference was found during the trial, as we replaced the multiple antipsychotics with risperidone (Table 2 ).

Comparing BPRS mean scores at baseline and $1,3,6,9,12,24$ and 36 showed a significant difference. Table 3 shows statistically significant improvements occurred from the $9^{\text {th }}$ week onward. Before the $9^{\text {th }}$ week of the trial, patients showed some recovery, but the results were not statistically significant. The improvements before the $9^{\text {th }}$ week

\section{Table 1: Antipsychotic polypharmacy distribution}

\begin{tabular}{|c|c|c|c|c|c|c|c|}
\hline $\begin{array}{l}\text { Type of } \\
\text { Polypharmacy }\end{array}$ & $\begin{array}{c}\text { First } \\
\text { Atypical } \\
\text { Antipsychotic }\end{array}$ & $\begin{array}{c}\text { Second } \\
\text { Atypical } \\
\text { Antipsychotic }\end{array}$ & $\begin{array}{c}\text { First } \\
\text { Typical } \\
\text { Antipsychotic }\end{array}$ & $\begin{array}{c}\text { Second } \\
\text { Typical } \\
\text { Antipsychotic }\end{array}$ & $\begin{array}{c}\text { Third } \\
\text { Typical } \\
\text { Antipsychotic }\end{array}$ & Frequency & Percent \\
\hline 4 entries & Risperidone & & Chlorpromazine & $\begin{array}{l}\text { Fluphenazine } \\
\text { Decanoate }\end{array}$ & Thiothixene & 1 & 1.92 \\
\hline \multirow[t]{9}{*}{3 entries } & Risperidone & & Chlorpromazine & $\begin{array}{c}\text { Fluphenazine } \\
\text { Decanoate }\end{array}$ & & 3 & 5.77 \\
\hline & Risperidone & & Chlorpromazine & Thiothixene & & 2 & 3.85 \\
\hline & Risperidone & & Thioridazine & $\begin{array}{c}\text { Fluphenazine } \\
\text { Decanoate }\end{array}$ & & 1 & 1.92 \\
\hline & Olanzapine & & $\begin{array}{c}\text { Fluphenazine } \\
\text { Decanoate }\end{array}$ & Thioridazine & & 1 & 1.92 \\
\hline & Olanzapine & & Fluphenazine & Haloperidol & & 1 & 1.92 \\
\hline & & & Decanoate & & & 1 & 1.92 \\
\hline & Olanzapine & & $\begin{array}{l}\text { Fluphenazine } \\
\text { Decanoate }\end{array}$ & Perphenazine & & 1 & 1.92 \\
\hline & Risperidone & Olanzapine & Chlorpromazine & & & 1 & 1.92 \\
\hline & & & Chlorpromazine & Perphenazine & Haloperidol & 1 & 1.92 \\
\hline \multirow[t]{15}{*}{2 entries } & Risperidone & & $\begin{array}{c}\text { Fluphenazine } \\
\text { Decanoate }\end{array}$ & & & 9 & 17.31 \\
\hline & Risperidone & & Chlorpromazine & & & 7 & 13.46 \\
\hline & Risperidone & & Haloperidol & & & 5 & 9.61 \\
\hline & & & Haloperidol & $\begin{array}{c}\text { Fluphenazine } \\
\text { Decanoate }\end{array}$ & & 4 & 7.69 \\
\hline & Risperidone & & Thiothixene & & & 2 & 3.85 \\
\hline & Risperidone & & Perphenazine & & & 2 & 3.85 \\
\hline & & & Chlorpromazine & Haloperidol & & 2 & 3.85 \\
\hline & Olanzapine & & Haloperidol & & & 2 & 3.85 \\
\hline & Risperidone & Olanzapine & & & & 1 & 1.92 \\
\hline & Risperidone & & Thioridazine & & & 1 & 1.92 \\
\hline & Olanzapine & & Chlorpromazine & & & 1 & 1.92 \\
\hline & Olanzapine & & Thioridazine & & & 1 & 1.92 \\
\hline & & & Chlorpromazine & $\begin{array}{c}\text { Fluphenazine } \\
\text { Decanoate }\end{array}$ & & 1 & 1.92 \\
\hline & & & Chlorpromazine & Thiothixene & & 1 & 1.92 \\
\hline & & & Chlorpromazine & Perphenazine & & 52 & 100 \\
\hline
\end{tabular}


Table 2: Comparison of BPRS positive and negative and general mean scores during treatment

\begin{tabular}{lcccccc} 
Duration of Treatment & \multicolumn{2}{c}{ Positive Score } & \multicolumn{2}{c}{ Negative Score } & \multicolumn{2}{c}{ General Score } \\
& Mean & SD & Mean & SD & Mean & SD \\
\hline Baseline & 9.56 & 4.85 & 8.38 & 3.91 & 10.87 & 4.05 \\
First day & 8.56 & 3.89 & 7.18 & 3.20 & 8.76 & 3.65 \\
Week 1 & 9.75 & 4.98 & 7.00 & 3.78 & 9.59 & 5.06 \\
Week 2 & 9.84 & 6.00 & 6.74 & 3.90 & 8.96 & 5.96 \\
Week 3 & 9.08 & 6.37 & 6.71 & 4.78 & 8.62 & 5.16 \\
Week 4 & 8.71 & 6.20 & 6.15 & 3.12 & 8.17 & 4.97 \\
Week 5 & 8.40 & 5.22 & 6.52 & 3.80 & 7.49 & 4.75 \\
Week 6 & 8.21 & 5.81 & 6.49 & 4.19 & 7.68 & 5.60 \\
Week 7 & 8.21 & 6.65 & 7.06 & 4.98 & 8.34 & 6.59 \\
Week 8 & 7.07 & 5.97 & 6.74 & 4.97 & 7.00 & 5.51 \\
Week 9 & 6.70 & 6.07 & 6.17 & 4.82 & 6.22 & 5.15 \\
Week 10 & 6.84 & 6.63 & 5.33 & 4.30 & 5.64 & 5.69 \\
Week 11 & 6.44 & 6.47 & 5.24 & 4.32 & 4.96 & 5.26 \\
Week 12 & 6.44 & 6.72 & 5.38 & 5.15 & 5.00 & 5.41 \\
Week 24 & 4.51 & 4.80 & 3.38 & 2.47 & 4.42 & 3.98
\end{tabular}

Table 3: Comparison of BPRS means total scores during treatment with baseline

\begin{tabular}{lcccc} 
Duration of Treatment & Mean & Median $(\mathbf{m i n}-\mathbf{m a x})$ & z value & P-value* \\
\hline Baseline & 28.5 & $29.0(11-59)$ & - & - \\
Day 1 & 25.3 & $25.0(7-55)$ & 1.765 & 0.078 \\
Week 3 & 25.6 & $23.0(2-71)$ & 2.837 & 0.005 \\
Week 6 & 23.4 & $20.0(3-75)$ & 3.393 & 0.001 \\
Week 9 & 19.9 & $17.5(2-70)$ & 3.683 & $<0.001$ \\
Week 12 & 17.5 & $12.0(1-71)$ & 3.981 & $<0.001$ \\
Week 24 & 12.8 & $10.0(1-52)$ & 5.431 & $<0.001$ \\
Week 36 & 7.58 & $6.0(1-42)$ & 5.778 & $<0.001$ \\
\hline
\end{tabular}

*Significant at level alpha $=0.05$ based on Wilcoxon Signed Ranks test (baseline scores with others)

Table 4: Comparing the BPRS positive and negative median (min-max) scores at the duration of treatment from a baseline to 36 weeks of trial male and female)

\begin{tabular}{lcccc} 
Duration of Treatment & \multicolumn{2}{c}{ BPRS Negative Score } & \multicolumn{2}{c}{ BPRS Positive Score } \\
& Male & Female & Male & Female \\
\hline Baseline & $11.0(5-20)$ & $7.0(2-15)$ & $12.0(6-19)$ & $8.0(2-26)$ \\
Day 1 & $6.0(3-15)$ & $7.0(2-15)$ & $10.0(3-21)$ & $8.0(1-19)$ \\
Week 3* & $9.5(3-19)$ & $5.0(0-19)$ & $17.5(4-29)$ & $7.0(1-15)$ \\
Week 6* & $9.0(4-17)$ & $4.0(1-14)$ & $11.5(4-29)$ & $6.0(1-13)$ \\
Week 9* & $10.0(2-18)$ & $4.0(0-13)$ & $8.5(0-29)$ & $5.0(0-16)$ \\
Week 12* & $11.5(3-21)$ & $3.0(0-12)$ & $15.0(0-26)$ & $4.0(0-11)$ \\
Week 24* & $5.0(3-10)$ & $2.0(0-7)$ & $10.0(3-19)$ & $2.0(0-10)$ \\
Week 36* & $3.5(0-7)$ & $1.0(0-6)$ & $5.0(3-12)$ & $1.0(0-9)$ \\
\hline
\end{tabular}

*Significant at level alpha $=0.05$ based on Mann-Whitney $U$ test

may be due to the patients cognitive improvements and the reduction of polypharmacy side effects. However, differentiation between symptom improvements and the effects of reducing polypharmacy side effects, such as anxiety and akathisia, are difficult. This issue is considered as one of our study limitations.

The results of the BPRS means scores among females and males were determined and it can be note that such mean scores decline in males less than in females (Table 4).

Table 5 shows improvements of $50 \%$ to $89 \%$ in 
Table 5: Reduction of symptoms at different time after monotherapy

\begin{tabular}{lccccccc} 
Reduction of symptoms & Week 1 & Week 3 & Week6 & Week 9 & Week 12 & Week 24 & Week 36 \\
\hline Amt. of reduction & $19(42.22)$ & $13(28.89)$ & $10(22.22)$ & $10(22.22)$ & $5(11.11)$ & $3(6.67)$ & $0(0.00)$ \\
$<25 \%$ & $12(26.67)$ & $14(31.11)$ & $10(22.22)$ & $3(6.67)$ & $6(13.13)$ & $3(6.67)$ & $2(4.44)$ \\
$25 \%$ to $49 \%$ & $11(24.44)$ & $9(20.00)$ & $14(31.11)$ & $15(33.33)$ & $10(22.22)$ & $7(15.26)$ & $2(4.44)$ \\
$50 \%$ to $89 \%$ & $3(6.67)$ & $9(20.00)$ & $11(24.45)$ & $15(33.33)$ & $20(44.44)$ & $31(68.89)$ & $35(77.78)$ \\
$>90 \%$ & $0(0.00)$ & $0(0.00)$ & $0(0.00)$ & $2(4.44)$ & $4(8.90)$ & $1(2.22)$ & $6(13.13)$
\end{tabular}

\section{Table 6: Friedman test of GAF score}

\begin{tabular}{lcccc} 
Follow up time & Mean Rank & Df & Statistics & p-value \\
\hline Baseline & 1.79 & 2 & 29.71 & $<0.001$ \\
Day1 & 1.82 & & & \\
Week 36 & 2.39 & & &
\end{tabular}

\section{Table 7: Friedman test of EPS score}

\begin{tabular}{lcccc} 
Follow up time & Mean Rank & Df & Statistics & p-value \\
\hline Baseline & 2.31 & 2 & 34.86 & $<0.001$ \\
Day1 & 2.23 & & & \\
Week 36 & 1.46 & & &
\end{tabular}

$6.67 \%$ of patients occurred in "Week 1" and in $77.78 \%$ of patients in "Week 36 ". As one can observe in this table, early overall symptom improvementsmay be due to the effect of reducing polypharmacy side effects.

Friedman`s qualitative Global Assessments of Functioning (GAF) and Extrapyramidal Syndrome (EPS) tests from baseline, day 1 and through the 36 weeks were performed (Tables 6 and 7).

Results for GAF score for baseline, "Day 1" and "week 36" showed "Mean Ranks" of 1.79, 1.82 and 2.39 respectively which were significant (Table 6). Results for EPS scores, during the above mentioned trial period are shown in Table 7 . Systematically, EPS assessments were done in all patients during the trial time points. None of the patients showed extrapyramidal manifestations such as tardive dyskinesia, akathisia and or Parkinsonian symptoms. Some patients had mild anxiety, which needed to be controlled nonmedically or with clonazepam up to the end of the 36 weeks of trial. Choosing 36 weeks for the trial period was arbitrary. Since patients' symptoms improved at the end of 36 weeks, we chose this period. For more accountable results, the authors have planned to continue this trial for a two-year period in the future. Mean and standard deviation were calculated from the baseline to the end of 36 weeks, to describe the BPRS scores. Afterward, a paired t -test was used to compare BPRS means at the duration of treatment with a baseline score. In addition, the Friedman test was used to compare GAF and also EPS scores at baseline, day 1 and week 36 . P-values of less than 0.05 were considered significant. Collection of data was implemented through an intensive training program with the participation of 2 psychiatrists and 2 psychologists. Inter-rating reliability was assessed and an overall agreement was reached. One psychiatrist, who was involved in the rating issue, asked not to interfere with scoring, in order to reduce the research bias. According to these statistical results, clinical recoveries, which were observed in the first weeks of the trial, were not statistically significant. As cited earlier, such early improvements may be related to the effect of gradual reducing polypharmacy side effects. 


\section{DISCUSSION}

The reasons for the use of a single antipsychotic, are the medication`s lower cost andfewer side effects. We do not know why these patients were on multiple antipsychotics in the past. Such cases traditionally have been handled by psychiatrists who were educated a number of years ago. In all likelihood, in those days, the injection mode of drug administration and prescribing multiple antipsychotics may have been more satisfactory; although these reasons may not why such therapeutic modalities were prescribed in the past. In our study, some patients showed recoveries in the first few weeks of trial, but these were not statistically significant. However, at the end of 36 weeks, all showed improvements with a significant difference. The reduction of polypharmacy side effects and the changes in neurotransmitter mechanisms may be contributed to such improvements. We selected the 36 weeks of the trial because we observed statistically significant clinical improvements at this time. Longer follow-ups are continuing for two years. The longer period of observation, will result in more reliable clinical evidence. The complexity of antipsychotic therapy and medication side effects are regarded as being equally significant. Antipsychotic side effects such as akathisia and restlessness may be assumed to be positive schizophrenic symptoms. Psychiatrists have a responsibility to monitor patients' responses and compliance while replacing polypharmacy with a single medication. This latter issue even makes the therapy more complex, since different antipsychotics are produced by different manufacturing companies. These complex issues may have negative effects on the care-provider and the patient alike. Regarding polypharmacy, we agree that the prescription of two antipsychotics which are known to be high potency $\mathrm{D}_{2}$ blocking agents such as risperidone + fluphenazine and risperidone + haloperidol may be considered to be poor treatment. Addressing the rationale behind such polypharmacy is not obvious. Using a single oral antipsychotic may result in better compliance, be less costly and be an easier route of administration. In this study, we observed that the positive, negative and general schizophrenic symptoms in elderly patients with chronic schizophrenia may be improved by replacing polypharmacy with risperidone. Polypharmacy was replaced with risperidone in 3-6 weeks and patients received monotherapy alone for the rest of the 36 weeks of the trial with significant improvements in outcome. Obviously, in some special circumstances, psychiatrists may prefer to prescribe polypharmacy wisely.

\section{CONCLUSION}

One may conclude, in order to replace polypharmacy with a single medication, psychiatrists are required to have knowledge, patience, experience and attention to detail. Detecting any undesired effects and preventing other more serious disorders is highly emphasized. A precise note should be taken of the patients`other co-morbidities and other nonpsychotic medication use which may interfere with their antipsychotics. Several worldwide studies have shown the benefits of switching polypharmacy to single medication. Other studies have supported the need for changing single to multiple antipsychotics. Our study may initiate more questions about the benefits and or the disadvantages of replacing polypharmacy with monotherapy. However, this study showed that the substitution of polypharmacy with risperidone may benefit elderly patients with chronic schizophrenia. We feel that such single medication therapy may increase compliance, decrease drug interactions, decrease side effects and lower cost. Since we were faced with some uncontrollable situations (time duration, number of patients selected, exclusion of some of cases because of their worsening clinical condition and exclusion because of the development of anew health disorder), further similar research should be undertaken. More importantly, due to the limited nature of this research data, we emphasize the need for further investigations on not only the 
advantages and disadvantages of antipsychotic polypharmacy, but also in regard to the effectiveness of such interventions in already prescribed multiple antipsychotic regimens. More investigation, to answer many complex and unexplained issues of polypharmacy, are suggested. Complex antipsychotic side effects such as akathisia and restlessness may be interpreted as positive schizophrenic symptoms. We assume that continuing medical education

\section{References:}

1. Viola R, Csukonyi K, Doró P, Janka Z, Soós G. Reasons for polypharmacy among psychiatric patients. Pharma World Sci 2004;26(3):143-7. [CrossRef]

2. Brend R, Herman E, Marc Z. Patterns of drug prescription in a psychiatric outpatient care unit, the issue of polypharmacy. German J Psychiatry 2008;11:1-6.

3. Xiang YT, Dickerson F, Kreyenbuhl J, Ungvari GS, Wang CY, Si TM, et al. Common use of antipsychotic polypharmacy in older Asian patients with schizophrenia (2001-2009). J Clin Psychopharmacol 2012;32(6):809-13. [CrossRef]

4. Linden M, Scheel T, Xaver EF. Dosage finding and outcome in the treatment of schizophrenic inpatients with amisulpride. Results of a drug utilization observation study. Hum Psychopharmacol 2004;19(2):111-9. [CrossRef]

5. Kennedy NB, Procyshyn RM. Rational antipsychotic polypharmacy. Can J Clin Pharmacol 2000;7(3):155-9.

6. Flaum M, Karp S, Parks J. Technical report of psychiatric polypharmacy. A series of technical reports prepared by the: National Association of State Mental Health Program Directors (NASMHPD) 2001;1-24.

7. Ghaemi N. Polypharmacy in Psychiatry. New York: Marcel Dekker, $1^{\text {st }}, 2002$.

8. Kingsbury SJ, Yi D, Simpson GM. Psychopharmacology: rational and irrational polypharmacy. Psychiatr Serv 2001; 52(8):1033-6. [CrossRef]

9. Ryan A, Jacques I. Medication compliance in older people. Elderly Care 1997;5:16-20.

10. Statistical Center of Iran. Management \& Planning Organization, Status of the Aged Nation Wide, Islamic Republic of Iran: 2002.

11. Mehl B, Santell J. Projecting future drug expenditures. Am J Health Syst Pharm 1999;56(1):31-9.

12. Wyles H, Rehman HU. Inappropriate polypharmacy in the elderly. Eur J Intern Med 2005;16(5):311-3. [CrossRef]

13. Woodard K, Franklin R. Treating elderly patients. Pharmacist 1999;24:HS7-16. enables the psychiatrist to follow current and available clinical practice guidelines. These latter facts may explain the reasons favoring prescribing of a single antipsychotic, not polypharmacy. Also, we feel that continuing nursing education programs and workshops dealing with the effects of polypharmacy are crucial for nurses and care providers. The patients compliance is another interesting research issue, which may be addressed in future studies.

14. Dawling S, Crome P. Clinical pharmacokinetic considerations in the elderly. An update. Clin Pharmacokinetic 1989;17(4):236-63. [CrossRef]

15. Hallas J, Worm J, Beck-Nielsen J, Gram LF, Grodum E, Damsbo N, et al. Drug related events and drug utilization in patients admitted to a geriatric hospital department. Dan Med Bull 1991;38(5):417-20.

16. Lamy PP. Prescribing for the Elderly. Littleton: Mess PSG Public Company; 1980.

17. Sadock BJ, Sadock VA. Kaplan and Sadock`s Synopsis of Psychiatry. $10^{\text {th }}$ ed. Philladelphia: Lippincott Williams and Wilkins: 2007.

18. Steven J, Megan L. Psychiatric Polypharmacy: the good, the bad, and the ugly. Psychiatric Times 2007;4:32.

19. Sadock BJ, Sadock VA. Kaplan and Sadock`s Comprehensive Textbook of Psychiatry. $9^{\text {th }}$ ed. Philadelphia: Lippincott Williams and Wilkins, 2009.

20. Rittmannsberger H, Meise U, Schauflinger K, Horvath E, Donat $\mathrm{H}$, Hinterhuber $\mathrm{H}$. Polypharmacy in psychiatric treatment. Patterns of psychotropic drug use in Austrian psychiatric clinics. Eur Psychiatry 1999;14(1):33-40. [CrossRef]

21. Weinmann S, Janssen B, Gaebel W. Switching antipsychotics in inpatient schizophrenia care: predictors and outcomes. J Clin Psychiatry 2004;65(8):1099-105. [CrossRef]

22. Tapp A, Wood A, Secret L, Erdmann J, Cubberley L, Kilzieh N. Combination antipsychotic therapy in clinical practice. Psychiatr Serv 2003;54(1):55-9. [CrossRef]

23. Ito C, Kubota Y, Sato M. A prospective survey on drug choice for prescriptions for admitted patients with schizophrenia. Psychiatry and Clinical Neurosciences 1999;53(Suppl):S35-40.

24. Najim H, Heath D, Singh P. Antipsychotic prescribing before clozapine in a community psychiatric hospital: a case note review. Psychiatr Danub 2013;25(Suppl 2):S165-70. 
25. Miller AL, Chiles JA, Chiles JK, Crismon ML, Rush AJ, Shon SP. The Texas medication algorithm project (TMAP) schizophrenia algorithms. Journal of Clinical Psychiatry 1999;60(10):649-57. [CrossRef]

26. Clark RE, Bartels SJ, Mellman TA, Peacock WJ. Recent trends in antipsychotic combination therapy of schizophrenia and schizoaffective disorder: implications for state mental health policy. Schizophr Bull 2002;28(1):75-84. [CrossRef]

27. Procyshyn RM, Kennedy NB, Tse G, Thompson B. Antipsychotic polypharmacy: a survey of discharge prescriptions from a tertiary care psychiatric institution. Canadian Journal of Psychiatry 2001;46(4): 334-9.

28. Williams CL, Johnstone BM, Kesterson JG, Javor KA Schmetzer AD. Evaluation of antipsychotic and. concomitant medication use patterns in patients with schizophrenia. Med Care 1999;37(4 Suppl Lilly):AS81-6.

29. Sim K, Su A, Fujii S, Yang SY, Chong MY, Ungvari GS et al. Antipsychotic polypharmacy in patients with schizophrenia: a multicentre comparative study in East Asia. Br J Clin Pharmacol 2004;58(2):178-83. [CrossRef]
30. Abdolahian E, Mohared F, Fyyazi MR. Haloperidol versus risperidone: a comparison of beneficial effect on cognitive function of patients with chronic schizophrenia. Iranian Journal of Psychiatry and Behavoral Sciences 2008;2(1):1420 .

31. Robiee M, Khorramdel K, et al. Factor structure, validity and reliability of the modified Yale-Brown obsessive compulsive scale for body dysmorphic disorder in students. Iranian Journal of Psychiatry and Clinical Psychology 2010;15(4):34250 .

32. Mokhtarzadeh A, Ghoreshzadeh MA, et al. Reliability and validity of Abridged versus of the Farsi version of scale to assess unawareness of mental disorders(SUMO) in psychotic mania. Iranian Journal of Psychiatry and Clinical Psychology 2010;16(31):181-6.

33. Akhondzadeh SH. Pharmacotherapy of schizophrenia. Iranian Journal of Psychiatry 2006;1(2):46-53. 